\title{
RCT of a Care Manager Intervention for Major Depression in Primary Care: 2-Year Costs for Patients With Physical vs Psychological Complaints
}

\author{
L. Miriam Dickinson, $P b D^{1}$ \\ Katbryn Rost, PbD ${ }^{1}$ \\ Paul A. Nutting, MD, MSPH \\ Carl E. Elliott, $M S^{1}$ \\ Robert D. Keeley, $M D^{1}$ \\ Harold Pincus, $M D^{3,4}$ \\ 'Department of Family Medicine, University \\ of Colorado Health Sciences Center, Aurora, \\ Colo \\ ${ }^{2}$ Center for Research Strategies, Denver, Colo \\ ${ }^{3}$ Department of Psychiatry, University \\ of Pittsburgh School of Medicine, \\ Pittsburgh, $\mathrm{Pa}$ \\ ${ }^{4}$ RAND - University of Pittsburgh Health \\ Institute, Pittsburgh, $\mathrm{Pa}$
}

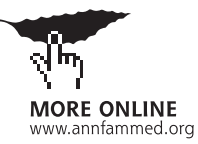

Conflicts of interest: none reported

\section{CORRESPONDING AUTHOR}

L. Miriam Dickinson, $\mathrm{PhD}$

Department of Family Medicine

UCHSC at Fitzsimons

PO Box 6508, Mail Stop F496

Aurora, CO 80045-0508

Miriam.Dickinson@UCHSC.edu

\begin{abstract}
PURPOSE Depression care management for primary care patients results in sustained improvement in clinical outcomes with diminishing costs over time. Clinical benefits, however, are concentrated primarily in patients who report to their primary care clinicians psychological rather than exclusively physical symptoms. This study proposes to determine whether the intervention affects outpatient costs differentially when comparing patients who have psychological with patients who have physical complaints.
\end{abstract}

METHODS We undertook a group-randomized controlled trial (RCT) of depression comparing intervention with usual care in 12 primary care practices. Intervention practices encouraged depressed patients to engage in active treatment, using nurses to provide regularly scheduled care management for 24 months. The study sample included 200 adults beginning a new depression treatment episode where patient presentation style could be identified. Outpatient costs were defined as intervention plus outpatient treatment costs for the 2 years. Cost-offset analysis used general linear mixed models, 2-part models, and bootstrapping to test hypotheses regarding a differential intervention effect by patients' style, and to obtain $95 \%$ confidence intervals for costs.

RESULTS Intervention effects on outpatient costs over time differed by patient style $(P<.05)$, resulting in a $\$ 980$ cost decrease for depressed patients who complain of psychological symptoms and a $\$ 1,378$ cost increase for depressed patients who complain of physical symptoms only.

CONCLUSIONS Depression intervention for a 2-year period produced observable clinical benefit with decreased outpatient costs for depressed patients who complain of psychological symptoms. It produced limited clinical benefit with increased costs, however, for depressed patients who complain exclusively of physical symptoms, suggesting the need for developing new intervention approaches for this group.

Ann Fam Med 2005;3:15-22. DOI: 10.1370/afm.216.

\section{INTRODUCTION}

$\square$ fectiveness trials show that enhanced depression treatment, with screening then telephone contacts from a nurse care manager for a 2 -year period, results in improved patient outcomes ${ }^{1,2}$ and diminishing costs with time. ${ }^{2}$ Recent evidence suggests that enhanced depression care may be effective primarily for patients who complain of psychological rather than exclusively physical symptoms. ${ }^{3}$ To date, investigators have been unable to show that primary care depression interventions can achieve cost offset (ie, reduce health care costs sufficiently to offset intervention costs). Cost offset, however, has not been explored in specific patient groups more 
or less likely to benefit from treatment. ${ }^{4}$ In this study we proposed to address the following question: Do the effects of a primary care depression intervention on outpatient health care costs differ by patients' style at the index visit? We hypothesized that enhanced depression treatment will achieve cost offset for depressed patients complaining of psychological complaints, because the intervention achieves more clinical improvement in this group. To reduce the chances of misclassification when patients reported psychological complaints at previous visits, we tested this hypothesis in depressed patients beginning a new treatment episode.

\section{METHODS}

\section{Experimental Design and Sample}

This study represents a secondary analysis of a subset of depressed patients beginning a new treatment episode who were enrolled in a group-randomized trial. ${ }^{1}$ After approval by the Human Research Advisory Committee of the University of Arkansas for Medical Sciences and the Colorado Multi-Institutional Review Board, the research team conducted the study in 12 primary care practices across the United States. Practices were randomized to enhanced or usual care after stratification on depression practice patterns. Patients aged 18 years and older coming to the practice for routine visits between April 1996 and September 1997 completed a 2-stage screening questionnaire administered by administrative staff, as well as an evaluation administered by a blinded member of the research team, to identify patients beginning a new treatment episode for depression ( $\geq 5$ major depression symptoms in the past 2 weeks, ${ }^{5}$ not currently receiving treatment with antidepressant medication, and having no specialty care in previous 6 months). Patients were excluded if they could not complete written screening questionnaires because of literacy problems; had no access to a telephone; did not intend to receive ongoing care in the clinic during the next year; had a life-threatening phys-

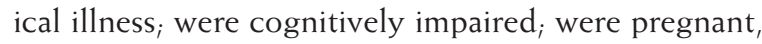
breastfeeding, or postpartum; or met study criteria for bereavement, mania, or alcohol dependence.

\section{Intervention}

Prior to patient enrollment, the research team provided brief training to participating physicians and nurse care managers in enhanced care practices. The goal was to encourage enhanced care practices to provide highquality acute care ${ }^{6}$ supplemented by systematic monitoring for 2 years. During the acute stage, care managers notified physicians that patients were depressed, educated patients about treatment options, and evaluated patients' response to treatment, alerting physicians when patients needed treatment adjustment. During systematic monitoring, care managers assessed each patient's depression symptoms during brief telephone calls encouraging continued treatment adherence or adjustment, and summarized relevant information to physicians in monthly written reports. Care managers reached $93.7 \%$ of 111 patients in enhanced care practices during the 24 months, for an average of 11.8 contacts $(\mathrm{SD}=5.9)$ per patient. Usual care practices were not given any training in depression management, nor were they systematically informed about which patients were participating in the study.

\section{Data Collection}

Of 11,006 eligible patients, 653 had positive screening results for depression on the 2 -stage screening questionnaire. Of these patients, $73.4 \%$ participated in further evaluation, and $44.0 \%$ met criteria for beginning a new treatment episode for major depression (Figure 1). Complete medical records with primary care physician documentation of symptoms at the index visit were available for 200 patients. After screening, data were collected from participating patients during structured telephone interviews by an interviewer blinded to intervention status, except for 3 patients whose practices were contacted to get updated location information. Concordant with an intent-to-treat design, patients who left the practice were interviewed again even though they could not participate in ongoing intervention. The 6-, 12-, 18-, and 24-month follow-up interviews conducted between October 1996 and September 1999 achieved response rates of $89.0 \%, 82.0 \%$, $70.0 \%$, and $68.0 \%$, respectively. A total of 181 patients $(90.0 \%)$ completed at least 1 follow-up interview and are included in longitudinal analyses.

Outpatient costs were defined as outpatient treatment costs plus intervention costs. As in other studies, ${ }^{7}$ because patients were either insured by multiple health plans or uninsured, costs for primary care and specialty mental health care visits, emergency department visits, and psychotropic medications were estimated from patient-reported utilization at each wave using standard methods $^{8-12}$ (Table 1 ). Intervention costs were estimated from salary plus fringe benefits for care managers and physicians, using care manager logs documenting time for patient screening, preparation for and delivery of the intervention, record keeping and review after the session, care manager and physician communication, and overhead. Cost offset is defined as a reduction in outpatient costs sufficient to offset intervention costs for a 2-year period, ie, 2-year outpatient costs (including intervention costs) for enhanced care patients that are lower or the same as for usual care patients.

The style in which patients reported their symp- 
toms was determined by medical record review in an effort to identify depressed patients who had at least 1 psychological complaint rather than physical complaints exclusively at the index visit (Table 1). (Coding for the complaints at the index visit is available as supplemental data in the Appendix, which can be found

sim online only at: http://www.annfammed.org/cgi/ content/full/3/1/15/DC1.) We selected covariates using regression methods to identify sociodemographic and clinical characteristics that predicted the outcome at $P<.20$ or differed between enhanced and usual care (Table 1).

\section{Data Analysis}

We conducted analyses in SAS 8.2 (SAS Institute, Cary, NC), log-transforming cost data before analysis to normalize distributions. ${ }^{13-15}$ General linear mixed models, ${ }^{16-20}$ adjusted for clustering of patients within prac-

Figure 1. Patient recruitment and participation flowchart.

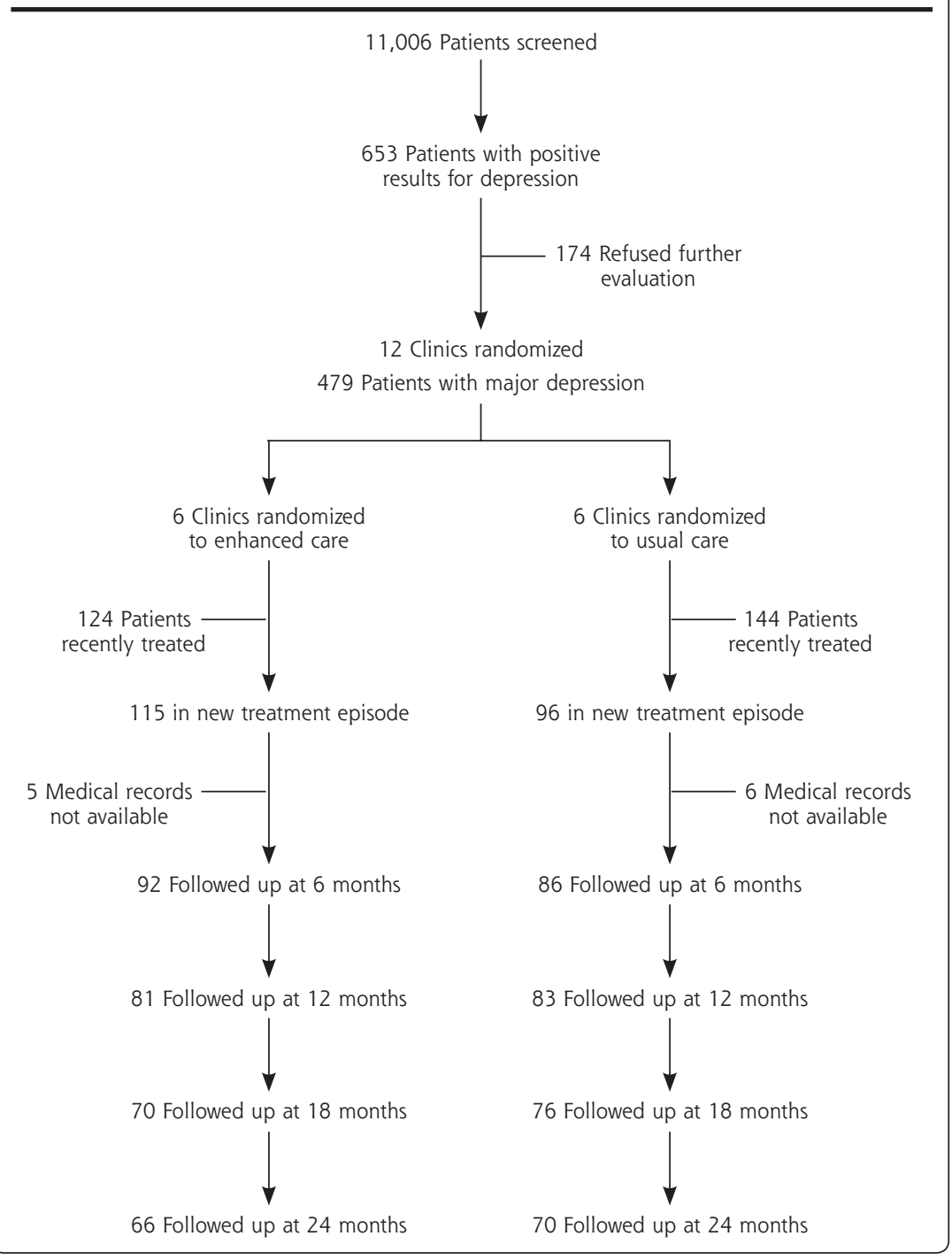

tice, were used to test whether there were differences between enhanced care and usual care patients on outpatient costs, and whether there was a differential intervention effect on costs by patient style. ${ }^{4}$ For component costs with sufficient sample size (primary care, medication, and emergency department visit costs), we used 2-part models $s^{7,21-24}$ to estimate costs when more than $10 \%$ of patients had $\$ 0$ costs. In 2 -part models the probability of any cost is estimated using logistic regression, then costs are estimated for patients with costs of less than $\$ 0$, and finally the 2 parts are combined to yield overall estimates. To enhance model stability, we totaled costs for each year and used repeated measures models. Patients who failed to complete a wave during the second half of year 1 or year 2 were considered to have $\$ 0$ costs for that wave. Although dropout was minimal and similar across treatment groups and patient styles, we performed a sensitivity analysis using last-value-carriedforward methods to replace missing values. To obtain less biased confidence intervals, we calculated outpatient costs for each of 1,000 bootstrap samples ${ }^{15,25,26}$ in the same manner, producing a distribution of outpatient cost estimates. ${ }^{8,21}$ Sensitivity analysis was performed to assess whether reclassification of the 9 patients (5 in enhanced care and 4 in usual care) whose styles were difficult to classify affected our findings.

\section{RESULTS \\ Participants}

At baseline, the mean age of the 200 participating patients was 43.4 years; $84.0 \%$ were women, $84.0 \%$ non-Hispanic white, $47.0 \%$ married, $63.5 \%$ employed, and $20.5 \%$ had less than a high school education. Patients reported $6.4(\mathrm{SD}=1.3)$ of 9 depressive criteria at baseline and averaged 2.1 $(\mathrm{SD}=1.9)$ physical comorbidities. Usual care patients were older than enhanced care patients (45.4 years vs 41.8 years, $P=.04)$, a difference we controlled for by including age as a covariate in all models. Other sociodemographic and clinical characteristics were similar across 


\section{Table 1. Operational Definition of Major Constructs \\ Intervention costs costs* \\ Patient style \\ Covariates \\ Time costs (salary plus fringe benefits) were derived from care manager logs for patient screening, preparation for and delivery of the patient intervention, postsession record keeping, care manager-physician communication, and administrative overhead \\ Outpatient visit costs based on patient-reported utilization were estimated using 1999 Medicare payment rates, classified by type and length: primary care physical at $\$ 35.51$, primary care mental health at $\$ 55.78$, specialty care psychiatrist $<45 \mathrm{~min}$ at $\$ 64.84$, specialty care psychiatrist $>45 \mathrm{~min}$ at $\$ 95.99$, specialty care other mental health provider $<45$ min at $\$ 59.06$, specialty care other mental health provider $>45$ min at $\$ 90.72$. Emergency department visit costs were estimated at $\$ 500$ per episode. Medication costs were estimated from patient-reported utilization of prescribed psycho- tropic medications, priced at the lowest average generic wholesale price per medication dosage reported in the 2000 Red Book of prescription drugs. All costs reported in this manuscript (for our study and other studies) were adjusted by the Consumer Price Index to reflect year 2000 us dollars \\ Defined as medical record notation by primary care physician that patient complained exclusively of physical symptoms at index visit vs $\geq 1$ of the Diagnostic and Statistical Manual - III-R symptoms listed in the Appendix. Nine patients (5\%) whose symptoms were difficult to categorize (weight gain/loss and abdominal distress) and who did not acknowledge any psycho- logical distress were initially categorized as complaining of physical symptoms. Inter-rater reliability for patient style was established in the following manner: (1) $20 \%$ of the 200 index visit medical records $(n=40)$ were selected at random; (2) 2 reviewers independently abstracted all patient complaints from those 40 index visits; (3) 2 reviewers independently categorized those 40 patients as having any psychological vs all physical complaints, achieving an inter-rater agreement on patient complaint style of $95 \%, \kappa=0.89^{3}$; and (4) 1 reviewer categorized patient style for the remaining patients \\ Baseline sociodemographic and clinical characteristics included age, minority status, insurance status, dysthymia in the pre- vious year, panic attacks in the previous year, presence of work limitations around the house, number of bed or cutback days, emotional role functioning as measured by the SF-36 ${ }^{11}$ (SF-36 Health Survey, the 36-item short form of the Medical Outcomes Study), and outpatient treatment costs for the 6 months before baseline \\ Note: Physical comorbidity not included because it did not differ significantly between enhanced and usual care subjects, nor did it significantly predict outpatient costs over time in models that controlled for the covariates listed in Table 1. \\ * Similar to other studies ${ }^{6}$ of primary care mental health interventions, we did not include inpatient costs because we did not observe intervention effects on hospitalization}

intervention and patient style, including outpatient costs during the 6 months before enrollment.

At the index visit, $66.0 \%$ of patients complained of physical symptoms only, and $34.0 \%$ complained of psychological symptoms only or mixed psychologicalphysical symptoms. The percentage of patients complaining of physical symptoms was similar for enhanced and usual care patients $(63 \%$ vs $70 \%$, respectively, $P=$ 28). As previously reported ${ }_{1}^{1,3}$ enhanced care resulted in improvement in depression treatment (eg, use of antidepressant medication) compared with usual care for patients who complained of both psychological and physical symptoms. There was modest (and very similar) clinical improvement during the first 6 months in usual care and enhanced care patients complaining of physical symptoms and usual care patients complaining of psychological symptoms. Enhanced care patients complaining of psychological symptoms, however, experienced significantly greater improvement in depression severity than all other groups. ${ }^{3}$

\section{Effect of Intervention and Patient Style on Costs}

In the entire sample, the intervention increased outpatient costs for the 2 years $(P<.01)$, but the 3 -way interaction term indicates that there were differential intervention effects by patient style (intervention* ${ }^{*}$ presentation style*time, $P=.04$ ). As shown in Figure 2, outpatient costs for enhanced care patients decreased with time, whereas outpatient costs for usual care patients who had psychological complaints increased considerably during year 2, and there was little change in outpatient costs for usual care patients who had physical complaints (Figure 2). During the 2 years, ongoing enhanced care for patients who had a psychological complaint at the beginning of a new depression treatment episode reduced outpatient costs by $\$ 980$ (Table 2). In contrast, ongoing enhanced care for patients who complained exclusively of physical symptoms at the beginning of a new depression treatment episode increased outpatient costs by $\$ 1,378$ for the 2 years. Results from sensitivity analysis with missing waves replaced by last value carried forward were similar ( $\$ 782$ reduction vs $\$ 1,027$ increase). Sensitivity analysis with reclassification of patients difficult to classify yielded similar results (available from authors on request), as did unadjusted analyses. When examining cost offset (enhanced care outpatient plus intervention costs the same or lower than usual care), we observed a potential cost offset 929 of 1,000 times among patients with psychological complaints compared with 2 of 1,000 times among patients with physical complaints in bootstrap replications.

Primary care and emergency department costs for the 2 years were relatively similar across groups, but there was a trend toward lower emergency department costs among enhanced care patients, especially those patients with psychological complaints (Table 2). Similarly, among patients with psychological complaints, medication costs for the 2 years averaged $\$ 387$ less for enhanced care patients than for usual care patients. Among patients with physical complaints, however, medication costs averaged $\$ 395$ more for enhanced 


\section{Figure 2. Impact of intervention on treatment costs for patients who have psychological and physical symptoms.}

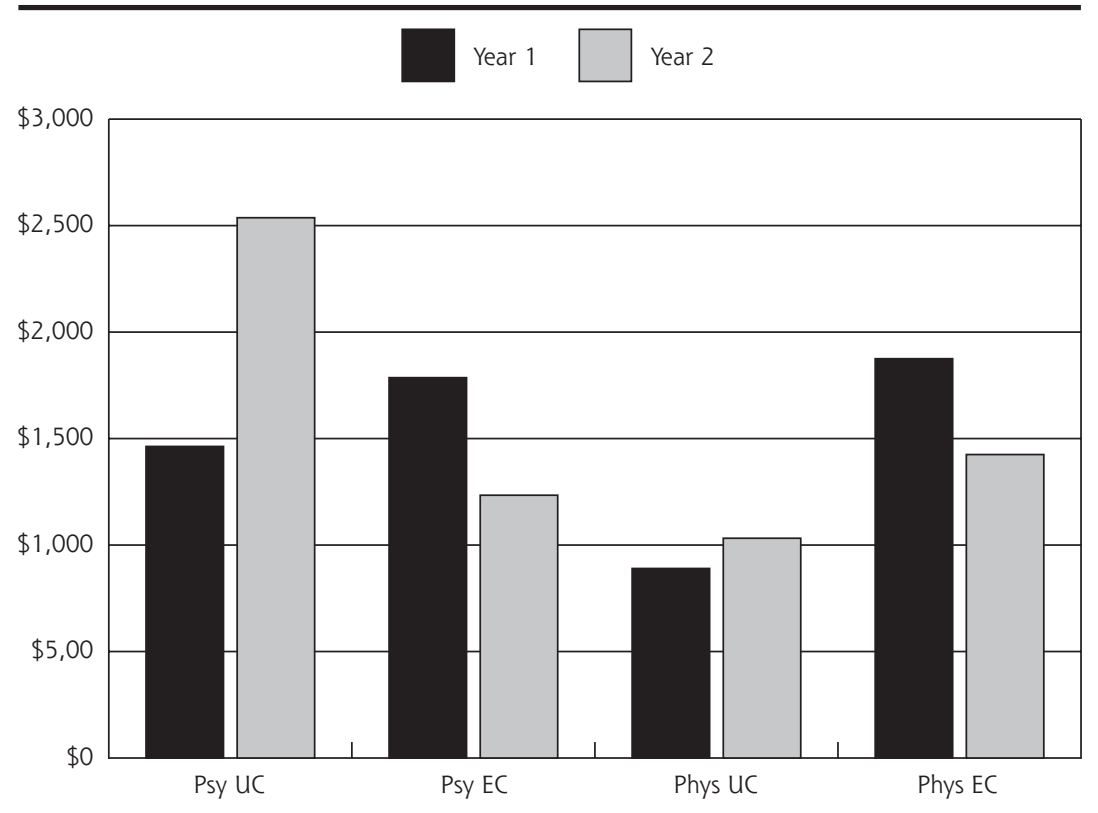

Psy UC: patients complaining of psychological symptoms, usual care; Psy EC: patients complaining of psychological symptoms, enhanced care; Phys UC: patients complaining of physical symptoms, usual care; Phys EC: patients complaining of physical symptoms, enhanced care.

ment episode improves clinical outcomes ${ }^{3}$ while reducing outpatient costs by $\$ 980$. In contrast, a 2-year ongoing intervention for patients who complain exclusively of physical symptoms at the beginning of a new depression treatment episode fails to improve clinical outcomes beyond usual care $^{3}$ while increasing outpatient costs by $\$ 1,378$ for 2 years

Using ongoing depression intervention to improve clinical outcomes with no increase to outpatient costs has recently been reported in efforts to improve primary care panic management. ${ }^{28}$ Acute intervention to improve primary care depression management improves clinical outcomes but increases outpatient costs by $\$ 256$ to $\$ 1,008$ for 1 year. ${ }^{2,22}$ We suspect that long-term care management is better able

care patients than for usual care patients. For primary care, medication, and emergency department costs, we observed potential cost offset in the bootstrap replications $85.9 \%, 79.1 \%$, and $89.7 \%$ of the time, respectively, among patients with psychological complaints in contrast to $13.0 \%, 0.0 \%$, and $63.8 \%$, respectively, for patients with physical complaints

\section{DISCUSSION}

In this study, a 2-year ongoing intervention for primary care patients who complain of psychological symptoms at the beginning of a new depression treat- to achieve cost offset because of greater sustained improvement in physical functioning, $1,7,29$ reducing patient demand for health care in the second year.

For patients who complain of psychological symptoms, ongoing intervention reduced outpatient costs during year 2 in contrast to increasing costs for usual care. Increasing costs in usual care patients who complain of psychological symptoms suggest that health plans undertaking systematic depression screening without providing other components of ongoing intervention may inadvertently stimulate patients who recognize they are depressed to seek escalating amounts of outpatient care. Although further study is needed to confirm

Table 2. Estimated Mean Costs for Total Outpatient and Selected Components, With $95 \%$ Confidence Intervals From Bootstrap Distributions

\begin{tabular}{|c|c|c|c|c|}
\hline \multirow[b]{2}{*}{ Component } & \multicolumn{2}{|c|}{ Usual Care } & \multicolumn{2}{|c|}{ Enhanced Care } \\
\hline & $\begin{array}{l}\text { Psychological Complaints } \\
\text { Mean \$ }(95 \% \mathrm{CI})\end{array}$ & $\begin{array}{l}\text { Physical Complaints } \\
\text { Mean \$ (95\% Cl) }\end{array}$ & $\begin{array}{l}\text { Psychological Complaints } \\
\text { Mean \$ }(95 \% \mathrm{CI})\end{array}$ & $\begin{array}{l}\text { Physical Complaints } \\
\text { Mean \$ }(95 \% \mathrm{Cl})\end{array}$ \\
\hline Primary care & $899(674-1,164)$ & $723(572-890)$ & 736 (554-953) & $849(697-1,021)$ \\
\hline Medications & $1,382(760-2,584)$ & $281(178-412)$ & $995(694-1,354)$ & $676(462-920)$ \\
\hline Emergency department & $1,105(700-1,598)$ & $1,076(677-1,728)$ & $802(607-1,036)$ & $934(719-1,196)$ \\
\hline Intervention & 0 & 0 & $291(272-311)$ & $292(277-308)$ \\
\hline $\begin{array}{l}\text { Total outpatient (including } \\
\text { intervention) }\end{array}$ & $4,000(2,959-5,407)$ & $1,922(1,402-2,665)$ & $3,020(2,354-3,864)$ & $3,300(2,629-4,073)$ \\
\hline
\end{tabular}


and expand our findings, these results have potentially important implications for comparing strategies for improving primary care depression management. Health plan administrators may wish to consider the possibility that (1) paying for screening alone may fail to improve outcomes $^{30,31}$ while increasing health plan costs for patients who recognize they are depressed, (2) paying for screening plus acute intervention may improve outcomes while increasing health plan costs, ${ }^{7,8,13,23}$ and (3) paying for screening plus ongoing intervention may improve outcomes for a select group of depressed patients while reducing health plan costs.

For depressed patients who complain of physical problems at the beginning of a new treatment episode, ongoing intervention increased costs with no additional clinical benefits from the added health care expenditures associated with improved depression management. We suspect that patients who had physical problems exclusively after acknowledging an average of 6 depression symptoms might also be suffering from somatization or somatic fixation, which often occurs with depression in primary care patients. ${ }^{32}$ This explanation is congruent with research showing that, in patients with somatization, outpatient medical utilization increases after mental health treatment. ${ }^{33}$ It is possible that comorbid somatization diminishes clinical gains and cost savings of improved depression management because patients have greater concern about physical problems even though physical disease is similar. ${ }^{33}$

Current primary care depression interventions do not target physician or patient beliefs about frequently co-occurring somatic symptoms. Thus, when depressed patients complain of physical problems, physicians who do not recognize that the symptoms might represent somatized depression or a somatization disorder are put in the uncomfortable position of choosing to address the physical problems for which the patient is seeking help or the emotional problem identified by the screening questionnaire. ${ }^{34}$ Additionally, the patient's belief that physical symptoms represent physical disease may reduce confidence in antidepressant medication treatment. ${ }^{35-37}$ Alternative explanations include treatment induction failure, early termination of antidepressant medications, chronic physical pain that prolongs the depressive state $^{38}$ or early-stage physical disease that would affect the subsequent course of depressive symptoms, general medical condition, and costs. Finally, despite meeting the study criteria for major depression, these patients may not actually have depression, or they may have a variant not captured in the current classification system, ie, a mixed somatization-depressive disorder, that has different prognostic and treatment implications.

Further research is needed to develop and test intervention strategies for depressed patients who have physical complaints. Cognitive behavioral therapy appears to be a particularly promising treatment for patients with somatic symptoms, a treatment that was not available to most patients in our study. ${ }^{39,40}$

Internal validity of our results is strengthened by use of a group-randomized design in the original study. Intent-to-treat analysis evaluates the impact of the intervention even in enhanced care patients who did not participate. Because enhanced care physicians were trained to improve depression management for patients participating in the study, they may have elicited and recorded chief complaints that were different from those recorded by usual care physicians; however, we could find no evidence that the intervention affected physician recording of patient complaints at the index visit. ${ }^{3}$ Although we were forced to rely on patient-reported health care utilization, we expect that any error this method introduced would bias our findings counter to our hypothesis, because of the potential for enhanced care patients to report care manager telephone contacts as outpatient visits. Although the cost offset we observed for the 2 years in patients with psychological complaints was robust across a number of modeling assumptions, we were unable to determine conclusively what types of utilization were reduced, because there was an insufficient number of patients who were using a particular service during the multiple waves of the study. ${ }^{24,41}$

External validity is enhanced because we tested the intervention in a clinically and socioeconomically heterogeneous patient population under natural conditions in which physicians and patients were free to select the treatments they preferred. The study was designed to be generalizable to primary care practices with diverse organizational and financing structures, as the intervention was tested in 12 geographically diverse, mixed-model practices caring for patients insured through numerous health plans. Although we were not able to follow up every patient for 2 years, we attempted to reduce the impact of sample loss by using modeling techniques based on all available data. Our findings cannot be generalized to primary care patients who are depressed despite recent treatment, because we could not reliably determine patient style at the index visit. We do not anticipate that the intervention will achieve a cost offset in this group because of the increased occurrence in this cohort of treatment-resistant depression, which requires more extensive intervention to achieve clinical benefit. ${ }^{42}$

This study contributes to observational studies supporting the potential for cost offset ${ }^{43-46}$ for mental health treatment by providing evidence from a randomized trial that outpatient costs for ongoing management of primary care depression for 2 years in targeted depressed populations offset the added health 
care expenditures associated with improved depression management. This finding suggests that interventions for targeted depressed patients could be implemented within the primary care practice without increasing overall health care costs and would allow health plans to adopt these interventions for targeted depressed populations without increasing health care premiums. The results suggest the need to examine whether other interventions can achieve cost offset in populations that can be identified at baseline as likely to benefit clinically. Finally, the study provides evidence that health services researchers, clinicians, and mental health professionals need to focus on an intensive effort to develop interventions to improve clinical and cost outcomes in patients whose depression may be complicated by somatization.

To read or post commentaries in response to this article, see it online at http://www.annfammed.org/cgi/content/full/3/1/15.

Key words: Cost-benefit analysis, depression; somatoform disorders; primary health care

Submitted December 22, 2003; submitted, revised, May 7, 2004; accepted May 24, 2004.

Funding support: This research was supported by National Institute of Mental Health grant R01 MH54444, Health Resources and Services Administration National Research Service Award 5T32 HP10006-10 and by a grant from the John D. and Catherine T. MacArthur Foundation. Dr. Rost is also supported by NIMH KO2 Independent Scientist Award MH63651.

Acknowledgments: The authors wish to acknowledge the physicians, office staff, and patients of participating primary care practices: Chatham Primary Care, Siler City, NC; Dunes Family Health Care, Reedsport, Ore; Eau Claire Family Medicine, Eau Claire, WI; Enid Family Medicine Clinic, Enid, Okla; Fergus Falls Medical Group, Fergus Falls, Minn; Health East Eastside Medical Center, St. Paul, Minn; Lynchburg Family Practice, Lynchburg, Va; Mile Bluff Clinic, Mauston, Wisc; Mountain Area Family Health, Asheville, NC; Northern Colorado Family Medicine, Greeley, Colo; Oakwood Health Care Center, Westland, Mich; Somerset Family Practice, Somerville, NJ; and University of North Dakota Center for Family Medicine, Minot, ND. We are extremely grateful to our colleagues in the Quality in Depression (QID) Cooperative Agreement, Will Manning, Jeffrey Pyne, Robert Keeley, Jeffrey Smith, Susan Moore, Joylyn Humphrey, Stephanie Mitchell, and research staff from the Center for Outcomes Research and Evaluation for the superb technical assistance and encouragement they offered. Finally, the authors thank anonymous reviewers of earlier drafts of this manuscript for their helpful comments.

\section{References}

1. Rost K, Nutting P, Smith JL, Elliott CE, Dickinson M. Managing depression as a chronic disease: a randomised trial of ongoing treatment in primary care. BMJ. 2002;325:934-939.

2. Rost K, Pyne JM, Dickinson LM, Elliott CE, deGruy F. The costeffectiveness of enhancing primary care depression management on an ongoing basis. Ann Fam Med. 2005;3:15-22.

3. Keeley RD, Smith JL, Nutting PA, Dickinson LM, Dickinson PW, Rost KM. Does a depression intervention result in improved outcomes for patients presenting with physical symptoms? J Gen Intern Med. 2004;19:615-623.
4. Kraemer HC, Wilson T, Fairburn CG, Agras WS. Mediators and moderators of treatment effects in randomized clinical trials. Arch Gen Psychiatry. 2002;59:877-883.

5. Zimmerman M, Coryell W. The inventory to diagnose depression (IDD): a self-report scale to diagnose major depressive disorder. J Consult Clin Psychol. 1987;5:55-59.

6. Depression Guideline Panel: Depression in Primary Care: Volume 2. Treatment of Major Depression. Clinical Practice Guideline, Number 5. (AHCPR Publication No. 93-0551). Rockville, MD; US Department of Health and Human Services, Public Health Service, Agency for Health Care Policy and Research; 1993.

7. Schoenbaum M, Unutzer J, Sherbourne C, et al. Cost-effectiveness of practice-initiated quality improvement for depression: results of a randomized, controlled trial. JAMA. 2001;286:1325-1330.

8. Lave JR, Frank RG, Schulberg HC, Kamlet MS. Cost-effectiveness of treatments for major depression in primary care practice. Arch Gen Psychiatry. 1998;55:645-651.

9. Rost K, Nutting PA, Smith J, Werner JJ. Designing and implementing a primary care intervention trial to improve the quality and outcome of care for major depression. Gen Hosp Psychiatry. 2000;22:66-77.

10. Gold MR, Siegel JE, Russell LB, Weinstein MC. Cost-Effectiveness in Health and Medicine. Oxford: Oxford University Press; 1996.

11. Hargreaves WA, Shumway M, Hu T, Cuffel B. Cost-Outcome Methods for Mental Health. San Diego, Calif: Academic Press; 1998.

12. Pyne JM, Rost KM, Farahati F, Smith J. One size fits some: the impact of patient treatment attitudes on the cost-effectiveness of a depression primary care intervention. Psychol Med. In press.

13. Simon GE, Manning WG, Katzelnick DJ, Pearson SD, Henk HJ Helstad CP. Cost-effectiveness of systematic depression treatment for high utilizers of general medical care. Arch Gen Psychiatry. 2001;58:181-187.

14. Laupacis A, Feeny D, Detsky AS, Tugwell PX. How attractive does a new technology have to be to warrant adoption and utilization? Tentative guidelines for using clinical and economic evaluations. Can Med Assoc J. 1992;146:473-481.

15. Manning WG. The logged dependent variable, heteroscedasticity, and the retransformation problem. J Health Econ. 1998;17:283-295.

16. Gibbons RD, Hedeker D, Elkin I, et al. Some conceptual and statistical issues in analysis of longitudinal psychiatric data: application to the NIMH treatment of depression collaborative research program dataset. Arch Gen Psychiatry. 1993;50:739-750.

17. Hedeker D, Gibbons R, Flay B. Random regression models for clustered data: with an example from smoking prevention research. J Clin Consult Psychol. 1994;62:285-296.

18. Bryk AS, Raudenbush SW. Hierarchical Linear Models: Applications and Data Analysis Methods. 1st ed. Newbury Park, Calif: Sage Publications; 1992.

19. Murray DM. Design and Analysis of Group-Randomized Trials. New York, NY: Oxford University Press; 1998.

20. Littell RC, Milliken GA, Stroup WW, Wolfinger RD. SAS System for Mixed Models. Cary, NC: SAS Institute, Inc; 1996.

21. Blough DK, Madden CW, Hombrook MC. Modeling risk using generalized linear models. J Health Econ. 1999;18:153-171.

22. Von Korff M, Katon W, Bush T, et al. Treatment costs, cost offset, and cost-effectiveness of collaborative management of depression. Psychosom Med. 1998;60:143-149.

23. Simon GE. Cost-effectiveness of a collaborative care program for primary care patients with persistent depression. Am J Psychiatry. 2001;158:1638-1644.

24. Olsen MK, Schafer JL. A two-part random-effects model for semicontinuous longitudinal data. J Am Stat Assoc. 2001;96:730-745. 
25. Goldman L, Weinstein M, Goldman PA, Williams LW. Cost-effectiveness of HMG-CoA reductase inhibition for primary and secondary prevention of coronary heart disease. JAMA. 1991;265:1145-1151.

26. Briggs $\mathrm{AH}$, Wonderling DE, Mooney $\mathrm{CZ}$. Pulling cost-effectiveness analysis up by its bootstraps: a non-parametric approach to confidence interval estimation. Health Econ. 1997;6:327-340.

27. Rost KM, Duan N, Rubenstein LV, et al. The Quality Improvement for Depression collaboration: general analytic strategies for a coordinated study of quality improvement in depression care. Gen Hosp Psychiatry. 2001;23:239-253.

28. Katon WJ, Roy-Byrne P, Russo J, Cowley D. Cost-effectiveness and cost offset of a collaborative care intervention for primary care patients with panic disorder. Arch Gen Psychiatry. 2002;59:1098-1104.

29. Sherbourne CD, Wells KB, Duan N, et al. Long-term effectiveness of disseminating quality improvement for depression in primary care. Arch Gen Psychiatry. 2001;58:696-703.

30. Linn LS, Yager J. The effect of screening, sensitization, and feedback on notation of depression. J Med Educ. 1980;55:942-949.

31. Dowrick C, Buchan I. Twelve month outcome of depression in general practice: does detection or disclosure make a difference? Brit Med J. 1995;311:1274-1276.

32. Dickinson WP, Dickinson LM, deGruy FV, et al. The somatization in primary care study: a tale of three diagnoses. Gen Hosp Psychiatry. 2003;25:1-7.

33. Fifer SK, Buesching DP, Henke CJ, et al. Functional status and somatization as predictors of medical offset in anxious and depressed patients. Value in Health. 2003;6:40-50.

34. Nutting PA, Rost $K$, Dickinson $M$, et al. Barriers to initiating depression treatment in primary care practice. J Gen Intern Med. 2002;17:103-111.

35. Williamson PS, Yates WR. The initial presentation of depression in family practice and psychiatric outpatients. Gen Hosp Psychiatry. 1989;11:188-193.

36. Garcia-Campayo J, Sanz-Carrillo C. A review of the differences between somatizing and psychologizing patients in primary care. Int Psychiatr Med. 1999;29:337-345.
37. O'Malley PG. Antidepressant therapy for unexplained symptoms and symptom syndromes: a clinical review. J Fam Pract. 1999;48:980-993.

38. Ohayon MM, Schatzberg AF. Using chronic pain to predict depressive morbidity in the general population. Arch Gen Psychiatry. 2003;60:39-47.

39. Looper KJ, Kirmayer LJ. Behavioral medicine approaches to somatoform disorders. J Consult Clin Psychol. 2002;70:810-827.

40. Raine R, Haines A, Sensky T, Hutchings A, Larkin K, Black N. Systematic review of mental health interventions for patients with common somatic symptoms: can research evidence from secondary care be extrapolated to primary care? BMJ. 2002;325:1082-1092.

41. Duan N. Smearing estimate: a nonparametric retransformation method. J Am Stat Assoc. 1983;78:605-610.

42. Rost K, Nutting P, Smith J, Werner J, Duan N. Improving depression outcomes in community primary care practice: a randomized trial of the QuEST intervention. J Gen Intern Med. 2001;16:143-149.

43. Borus JF, Olendzki MC, Kessler L, et al. The 'offset effect' of mental health treatment on ambulatory medical care utilization and charges: month-by-month and grouped-month analyses of a five-year study. Arch Gen Psychiatry. 1985;42:573-580.

44. Hankin JR, Kessler LG, Goldberg ID, Steinwachs DM, Starfield BH. A longitudinal study of offset in the use of nonpsychiatric services following specialized mental health care. Med Care. 1983;21:10991110.

45. Salvador-Carulla L, Segui J, Fernandez-Cano P, Canet J. Costs and offset effect in panic disorders. Br J Psychiatry Suppl. 1995;166:23-28

46. Thompson D, Hylan TR, McMullen W, Romeis ME, Buesching D, Oster $\mathrm{G}$. Predictors of a medical-offset effect among patients receiving antidepressant therapy. Am J Psychiatry. 1998;155:824-827.

47. McHorney CA, Ware JE, Jr., Raczek AE. The MOS 36-item short-form health survey (SF-36): II. Psychometric and clinical tests of validity in measuring physical and mental health constructs. Med Care. 1993:31:247-263. 